\title{
T cell subsets rise again
}

Interleukin-22 (IL-22)-producing Thelper cells (or $\mathrm{T}_{\mathrm{H}} 22$ cells) become the latest addition to the ever increasing diversity of $\mathrm{CD} 4^{+} \mathrm{T}_{\mathrm{H}}$ cell subsets, as reported in two recent papers published in Nature Immunology. This new subset of human $\mathrm{T}$ cells, shown to be distinct from $\mathrm{T}_{\mathrm{H}} 1, \mathrm{~T}_{\mathrm{H}} 2$ and $\mathrm{T}_{\mathrm{H}} 17$ cells, is characterized by a propensity to express skin-homing chemokine receptors and to produce IL-22 but not IL-17 or interferon- $\gamma$ (IFN $\gamma$ ).

IL-22 has been shown to be produced mainly by $\mathrm{T}_{\mathrm{H}} 17$ cells and most recently by some natural killer cell-like subsets that are commonly found at mucosal surfaces, where it acts on epithelial cells and keratinocytes and is thought to be involved in tissue homeostasis and wound healing. However, there have been inconsistent data on whether IL-22 has a protective or pathogenic effect in disorders such as Crohn's disease and psoriasis. So, Duhen et al. and Trifari et al. investigated whether the effect of IL-22 might depend on the presence of distinct populations of T cells that can produce IL-22 alone or in association with inflammatory cytokines such as IL-17 and IFN $\gamma$.

Both groups analysed cytokine production by subsets of human $\mathrm{CD} 4^{+}$memory $\mathrm{T}$ cells that were distinguished on the basis of expression of chemokine receptors. This analysis led to the identification of a population of memory $\mathrm{T}$ cells that expressed CC-chemokine receptor 6 (CCR6, which is characteristic of $\mathrm{T}_{\mathrm{H}} 17$ cells) and the skin-homing receptors CCR4 and CCR10 and that produced large amounts of IL-22 but no or small amounts of IL-17 and IFN $\gamma$. By contrast, CCR10- $\mathrm{T}$ cell subsets did not produce IL-22, or produced IL-22 together with IL-17 or IL-17 and IFN $\gamma$. The IL-22-producing

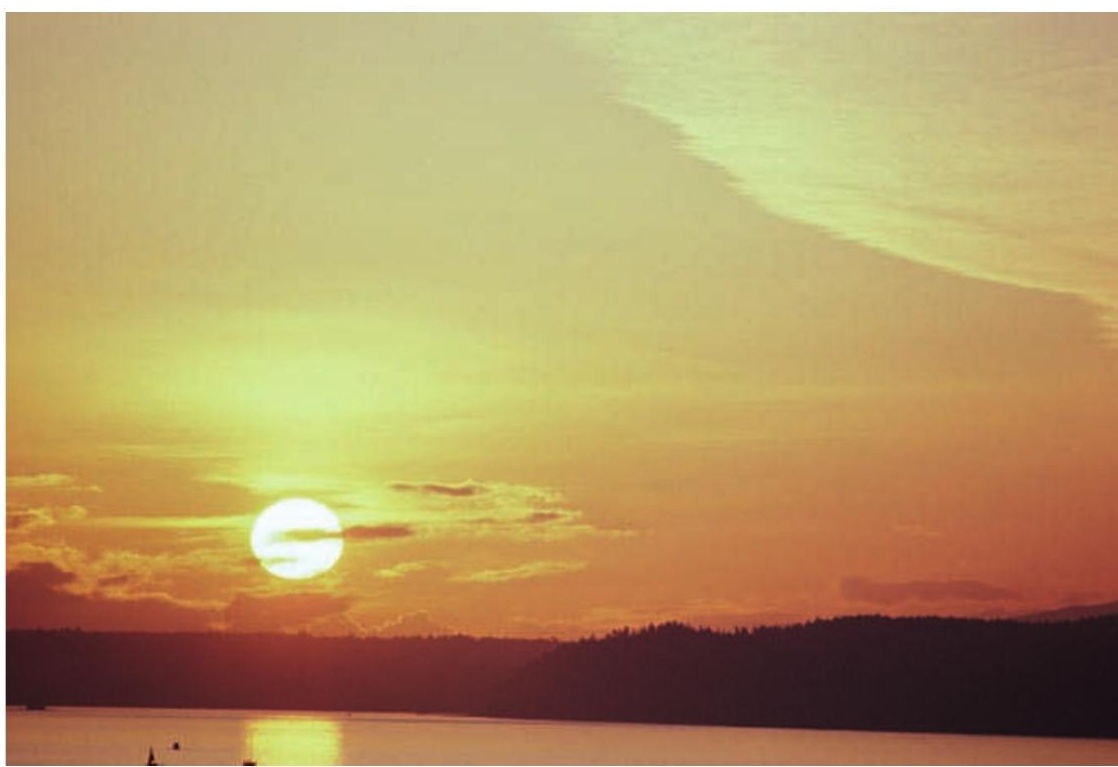

$\mathrm{CCR}^{+} \mathrm{CCR} 4^{+} \mathrm{CCR} 10^{+}$phenotype seemed to be stable, as cells cultured for $\sim 7$ days or cloned and cultured for several weeks retained the propensity to produce only IL-22. Further analysis revealed that IL-22 production was less dependent on the expression of the transcription factor retinoic acid receptor-related orphan receptor- $\gamma \mathrm{t}$ (ROR $\gamma \mathrm{t}$ ) compared with IL-17 production, but seemed to involve the transcription factor aryl hydrocarbon receptor (AHR), which interacts with environmental toxins and endogenous tryptophan metabolites and is also thought to regulate $\mathrm{T}_{\mathrm{H}} 17$ cells.

Duhen et al. showed that $\mathrm{T}_{\mathrm{H}} 22$ cells could be generated in vitro from naive $\mathrm{CD} 4^{+} \mathrm{T}$ cells in the presence of IL-6 and tumour necrosis factor (TNF), that plasmacytoid dendritic cells (DCs) were more efficient than conventional DCs at supporting $\mathrm{T}_{\mathrm{H}} 22$ cell differentiation and that induction of CCR10 expression by these cells depended on the presence of active vitamin $\mathrm{D}_{3}$ metabolites. Addition of
IL-1 $\beta$ to the cultures shifted the balance from $\mathrm{T}_{\mathrm{H}} 22$ cell differentiation to $\mathrm{T}_{\mathrm{H}} 17$ cell differentiation. Trifari et al. showed that supplementing their naive $\mathrm{T}$ cell cultures with AHR agonists (in $\mathrm{T}_{\mathrm{H}} 17$ cell-polarizing or non-polarizing conditions) favoured the differentiation of $\mathrm{T}_{\mathrm{H}} 22$ cells.

Together, these studies support the idea that environmental factors at sites such as the skin might alter the balance between $\mathrm{T}_{\mathrm{H}} 22$ and $\mathrm{T}_{\mathrm{H}} 17$ cells and influence disease, although the relative contributions of these T cell subsets in various skin disorders requires further study.

\section{Lucy Bird}

ORIGINAL RESEARCH PAPERS Duhen, T.

Geiger, R., Jarrossay, D., Lanzavecchia, A. \& Sallusto, F. Production of interleukin 22 but not interleukin 17 by a subset of human skin-homing memory T cells. Nature Immunol. 5 Jul 2009 (doi:10.1038/ni.1767)| Trifari, S., Kaplan, C. D., Tran, E. H., Crellin, N. K. \& Spits, H. Identification of a human helper $\mathrm{T}$ cell population that has abundant production of interleukin 22 and is distinct from $T_{H}-17, T_{H} 1$ and $T_{H} 2$ cells. Nature Immunol. 5 Jul 2009 (doi:10.1038/ni.1770) 